\title{
Stela do Patrocínio: um passado de areia
}

[ Stela do Patrocínio: a past of sand

\section{Solange de Oliveira ${ }^{\mathrm{I}}$}

RESUMO-Este trabalho propõe uma leitura de abordagem fenomenológica sobre a obra de Stela do Patrocínio, interditada na Colônia Juliano Moreira por cerca 30 anos. Sua poesia expressa para além da beleza cruel. Impõe uma experiência de engajamento, como se o olhar da poetisa invadisse o leitor e nele se instalasse como um órgão de sentidos. Este ensaio celebra a alteridade como fonte de conhecimento e de possibilidades que se abrem, quando nos permitimos adentrar em um mundo impensável até então. O intuito é suscitar a resistência ao pensamento homogêneo e convocar à tomada de posição. • PALAVRAS-

CHAVE - Stela do Patrocínio; arte ínsita; fenomenologia. - ABSTRACT - This work proposes a phenomenological approach on the poetry of Stela do Patrocínio. She was interdict at Juliano Moreira Colony for about 30 years. Her poetry expresses far beyond cruel beauty. Such an experience of engagement is imposed, as if the gaze of the poet invaded the reader and installed that impression on him as an organ of the senses. This essay celebrates otherness as a source of knowledge and of the possibilities that open up when we allow ourselves to enter into an unthinkable world. The aim of this work is to raise resistance to homogeneous thinking, and to call for a position to be taken. - KEYWORDS - Stela do Patrocínio; inherent art; phenomenology.

Recebido em I5 de junho de $202 \mathrm{I}$

Aprovado em 27 de julho de $202 I$

OLIVEIRA, Solange de. Stela do Patrocínio: um passado de areia. Revista do Instituto de Estudos Brasileiros, Brasil, n. 79, p. I24-I33, ago. 202I.

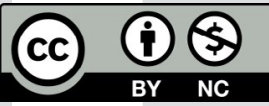

DOI: https://doi.org/Io.II606/issn.23I6-90IX.vIi79pI24-I33

I Universidade Federal de Sergipe (UFS, São Cristóvão, SE, Brasil). 
O mundo que eu tô botando pra dentro

De tanto olhar

Olhar

De tanto enxergar olhar ver espiar

Sentir e notar

Tô botando tudo pra dentro porque botando pra dentro eu botei pra fora.

(Stela do Patrocínio, 200I, p. I52).

Stela do Patrocínio aguça imagens borradas e cruas. Expressa-se torcendo as palavras, espoliando-as sem pudor. Pouco se sabe sobre sua origem, não foge ao inelutável destino de negros e pobres, os indesejáveis sociais. Filha de Manoel e Zilda Xavier do Patrocínio, Stela nasceu no Rio de Janeiro, em 9 de janeiro de I94I, e conquistou apenas a instrução secundária. Antes de sua incursão pelo mundo dos eletrochoques e das infindáveis doses de Haldol, trabalhou como empregada doméstica na Urca, na mesma casa onde sua mãe havia enlouquecido. Em I5 de agosto de I962, com apenas 2I anos, e cumprindo a sina familiar, iniciou sua incursão intramuros no Centro Psiquiátrico Pedro II, no Engenho de Dentro, de onde foi transferida para a Colônia Juliano Moreira quatro anos mais tarde (PATROCÍNIO, 200I, p. I55).

Mulher sensível, Stela acumula dicotomias: conserva gostos comezinhos, como leite condensado, biscoito de chocolate, cigarros e blusas azuis (POMPERMAIER, 20I7), e, por outro lado, se expressa com escandalosa sofisticação sobre as coisas da vida. Essa conhecença foi lapidada pela sobrevida asilar e pela excepcional habilidade de tonalizar a miséria e a solidão com um olhar apurado. Os 30 anos de asilo e esquecimento foram saciados em I992, quando uma infecção generalizada calou seu inspirado discurso após dois longos meses de agonia.

A fala, entre espirituosa e poética, foi postumamente organizada em um livro indicado ao Prêmio Jabuti de 2002. Sua história se soma à massa homogênea de excluídos asilados, e denuncia o tratamento praticado em um período histórico do qual não nos orgulhamos, marcado pela eugenia, a exemplo do que decorreu 
com Arthur Bispo do Rosario², aliás, na mesma instituição. À primeira vista, o traço comum entre Stela e Bispo é a fatura de uma vida de abandono e privações intramuros. Também os aproxima a beleza ${ }^{3}$ de suas expressões artísticas, que esbanjam sentidos reinventados. A fonte de seu aprendizado é a miséria do cotidiano asilar e as memórias de uma vida que ficou no passado, do lado de fora dos portões da instituição.

Eu vim pra Colônia porque eu estava andando na Rua Voluntários da Pátria ao lado do Luís, com um óculos, vestido azul, sapato preto, com uma bolsa branca com um dinheirinho dentro, porque eu ia pegar o ônibus e ia saltar na Central do Brasil, na Central do Brasil eu ia tomar uma refeição [...] aí eu peguei o carro ainda na Rua Voluntários da Pátria com o Luís [...], o Luís foi ao bar, eu estava ao lado do Luís [...] ele tomou a refeição sozinho, não pagou pra mim [...] quando ele acabou nós saímos, eu perdi o óculos, perdi o óculos, perdi o óculos que estava comigo, um óculos escuro, parecia que ele tinha me dado um bofetão na cara pra mim perder o óculos [...] eu caí por cima do óculos e o óculos e eu ficamos no chão, aí veio, aí veio uma velhinha, na porta do apartamento dela, me levantou, disse que não tinha sido nada, pra mim parar de ficar chorando, aí veio uma dona me botou pra dentro do Posto do Pronto Socorro perto da Praia de Botafogo, e lá, eu dentro do Pronto Socorro, ela me aplicou uma injeção, me deu um remédio, me fez um eletrochoque, me mandou tomar um banho de chuveiro, mandou procurar mesa, cadeira, cadeira, mesa [...] e aí chamou uma ambulância, uma ambulância assistência e disse: "carreguem ela" [..... (PATROCÍNIO, 200I, p. 48)4.

Stela simplesmente habita o mundo ao sabor das experiências, negligencia juízos e opiniões. Sua rara capacidade de reinscrever agruras em outros termos não se sedimenta sobre antecedentes, mas os sustenta de forma que todo esse repertório venha coabitá-la e, em um ímpeto expressivo, ganhe voz.

Eu estava com saúde

Adoeci

Eu não ia adoecer sozinha não

2 Sobre a questão asilar na vida e obra do artista sergipano, ver: Oliveira, 2016.

3 Não é o caso e não pretendemos adentrar na discussão sobre o conceito de belo artístico, assunto bastante extenso. Mas, no intuito de melhor delimitar o sentido em que aqui o empregamos - segundo uma noção do filósofo italiano Luigi Pareyson, explicitamos rapidamente sua posição, a qual nos parece cabível neste estudo. Até o Romantismo, diz Pareyson (2001), que a lei da arte foi a beleza. Depois, a beleza canônica foi gradativamente sendo substituída pela beleza da expressão de um verdadeiro sentimento de interioridade. Com o despontar da modernidade, o conceito de belo permitiu a incorporação de objetos feios e repugnantes e foi ganhando consideração menos estrita no campo da arte, além de descolar-se cada vez mais de um saber leigo e subjetivo do termo. Aderiu-se a uma enorme gama de predicados que tendem para uma doutrina mais da sensibilidade que da plasticidade - "a beleza não é lei mas resultado da arte: não seu objeto ou fim, mas seu efeito e êxito, não que a obra de arte seja artística porque bela, mas é bela porque artística” (PAREYSON, 200I, p. I38).

4 Em todas as citações de Stela do Patrocínio, foram mantidas a grafia, a concordância verbal e a pontuação originais de seu livro. 
Mas eu estava com saúde

Estava com muita saúde

Me adoeceram

Me internaram no hospital

E me deixaram internada

E agora eu vivo no hospital como doente

O hospital parece uma casa

O hospital é um hospital

(PATROCÍNIO, 200I, p. 5I).

Mas nossa índole cartesiana está justamente à revelia dessa espontaneidade. Fomos incentivados a iluminar aquilo que se sabe, para que assuma o protagonismo sobre qualquer intuição. Transitamos nos limites familiares de uma fronteira segura, orientados por um olhar sobre o mundo constituído pelo pensamento já instalado: o mundo é aquilo sobre o qual reflito. Nossa cultura e sociabilidade nos levaram a confiar irrestritamente em um letramento excessivo. Essa noção é de Henri Bergson (2006), para quem o conhecimento letrado não deve ser abandonado, mas relativizado e reinventado. Devemos ajustar nossos passos ao seu andamento, adotando seus gestos e suas atitudes e, assim, a inteligência virá mais tarde para matizá-lo, a exemplo de como se desenrola o aprendizado na infância.

Assim, somos inclinados a um conhecimento do mundo que se dá pela ciência, no entanto, a experiência do mundo é encarnada e, sem ela, os símbolos da ciência se esvaziam: "Todo o universo da ciência é constituído sobre o mundo vivido [...]. A ciência não tem e não terá jamais o mesmo sentido de ser que o mundo percebido, pela simples razão de que ela é uma determinação ou uma explicação dele" (MERLEAU-PONTY, 2006, p. 3). O saber objetivo - como a psicologia, as patologias da expressão e a linguística - destina-se a este mundo o qual habitamos e não a um mundo ideal, conceitual e, para que nele nos situemos como uma ponte ou uma via de ligação, a linguagem é uma forma de mediação e esclarecimento. Os fatos de linguagem vivem em nós, estamos inexoravelmente atados a eles; são uma "fala que se enuncia em nós, e à qual, em meio ao nosso trabalho científico, permanecemos ligados como por um cordão umbilical” (MERLEAU-PONTY, 20I2, p. 46). Nada há na poesia de Stela do Patrocínio que suscite esse mundo explicado e comprovado pelas verdades científicas. A fala da poetisa se anuncia em nós, e nos convoca a uma tomada de posição diante de seu estilo.

Seja prosaico, seja poético ou plástico, se responde unicamente a relatos, teses e conclusões articulados na coerência das certezas científicas, o pronunciamento empobrece, pois se mantém aquém das infinitas relações de signos e de significações. É apenas verdade desmaiada. Se, ao contrário, opera ou imprime ativamente um estilo, pode expressar uma significação oblíqua ou latente. Merleau-Ponty (I99I) tem uma posição peculiar sobre a questão do estilo nas expressões artísticas. Em tempo, enquanto a visibilidade do fato artístico é turva, o reconhecimento do estilo do autor por parte do leitor é flagrante e, às vezes, imediato.

O estilo é um modo de formulação através do qual Stela se faz reconhecer em sua 
escritura. É um determinado meio de recriar o mundo a partir de um repertório de valores. Ou Stela atribui uma expressão de certa significação ou, então, sua escritura é a consequência de uma visão. Assim, o estilo não pode se restringir apenas a um meio, como se tivesse per si o poder de se fazer reconhecer fora desse contato existencial, como se fosse um fim (MERLEAU-PONTY, I99I, p. 55). De modo análogo, a palavra também não se coloca exclusivamente a serviço de uma finalidade objetiva. O ponto no mundo que ocupa e do qual Stela fala é único; também suas experiências são inalienáveis, mas têm o poder de nos penetrar e articular em nós um pensamento que era impensável até esse contato unívoco.

Não há como buscar correspondência, não há fórmulas, nem reciprocidade. A palavra muda, repleta de modulações, insinuações e silêncios, a exemplo das tentativas, erros e decisões mal tomadas entre uma e outra escritura ou pincelada - ou nos alinhavos do bordado de Arthur Bispo do Rosario -, em um só gesto pode condensar "toda a verdade de um homem" (MERLEAU-PONTY, I99I, p. 8I). É na palavra não pronunciada, no traço hesitante, ou mesmo na iniciativa abandonada, que estão a discussão e a busca inesgotáveis.

É dito: pelo chão você não pode ficar

Porque lugar de cabeça é na cabeça

Lugar de corpo é no corpo

Pelas paredes você também não pode

Pelas camas também você não vai poder ficar

Pelo espaço vazio você também não vai poder ficar

Porque lugar de cabeça é na cabeça

Lugar de corpo é no corpo

(PATROCÍNIO, 200I, p. 52).

A expressão guarda mais do que ideias e conceitos; suas matrizes, seus emblemas, e a própria linguagem são quem nos ensina seu segredo: "Sua opacidade, sua obstinada referência a si própria, suas retrospecções e seus fechamentos em si mesma são justamente o que faz dela um poder espiritual: pois torna-se por sua vez algo como um universo capaz de alojar em si as próprias coisas depois de as ter transformado em sentido das coisas" (MERLEAU-PONTY, I99I, p. 43).

Assim, o sentido é enraizado no vivido, como fica evidente em certas obras. No caso de Stela do Patrocínio, a expressão mergulha em um mundo nada glamuroso, e de lá se retira o alimento, como a flor de lótus cintilando ao sol, com as raízes fixadas na lama. Surge em um ímpeto de insubordinação, contrariando todas as prerrogativas, e projeta suas pétalas para além da escuridão.

Perdi o gosto o prazer o desejo a vontade o querer (PATROCÍNIO, 200I, p. I2I).

De fato, expressões inatas, de iletrados artisticamente, subletrados ou, no limite, completamente iletrados têm ganho espaço e relativa notoriedade no mundo contemporâneo, diverso e multicultural, e já são admitidas nos salões. 
Resta saber se seus protagonistas também são. Nesse sentido, a denominação "arte ínsita" oferece certo distanciamento sobre a disputa política no campo da arte. Essa expressão foi proposta pela primeira vez nas Trienais de Bratislava, em I972, mas acabou caindo em desuso. Sua procedência é o latim, in situ, e significa inato, congênito, não formado, original. Tenho procurado adotar a expressão arte ínsita, que cobre a expectativa sobre a produção desses autores. É lícita, justamente na medida em que coloca em relevo o conhecimento inato que o sujeito traz consigo para esse mundo, e é apropriada para referir tais fenômenos, por causa da expressividade e da ontologia que essas obras reivindicam e oferecem. Além disso, é uma contribuição democrática, não distingue ou nivela sujeitos segundo o grau de conhecimento formal adquirido.

Para se realizar, a obra solicita quem a faz, óbvio, mas também quem a acessa, instigando questões que estão além do prazer da fruição, pois traspassa ou fixa-se nos espectadores como um órgão do espírito, fazendo-os ver sob nova perspectiva que se incorpora a um mundo novo, que jamais pensaram e do qual, a partir de agora, não mais poderiam prescindir ${ }^{5}$.

A fala espirituosa de Stela do Patrocínio só pode se apresentar como uma linguagem que não se estrutura através de conceitos. Sua arte nos introduz em um mundo novo, do qual passamos a participar por uma força da verdade que se instaura a partir das expressões do artista encarnado. A partir do momento em que embarcamos em seu estilo, que não é senão seu modo próprio de se colocar em situação, esse estilo só ganha tônus e adesão se mergulhado nas experiências mundanas de seus interlocutores, no caso de Stela, o cotidiano intramuros. Em uma relação peculiar e inédita, os signos que Stela faz dançar sob nossos olhos se fazem exprimir de tal modo que, paradoxalmente, são imediatamente esquecidos para ceder lugar a um sentido que nos atinge de maneira ainda mais contundente: é a manifestação de uma palavra verdadeira, capaz de libertar um "sentido cativo na coisa” (MERLEAU-PONTY, I99I, p. 45). Esse desvelamento mágico e insólito surge da relação inédita que Stela põe em obra em sua poesia. Desse modo, a única condição para que sua obra a expresse é que seja feita, que exista.

Empenhando irredutivelmente suas experiências nesse empreendimento engajado, e valendo-se dos mesmos signos tão desgastados pelo uso rotineiro e monótono, a poetisa os coloca em situação de modo particular e intransferível - é o seu estilo - e faz surgir um sentido inaudito. E, assim, o leitor é pego de assalto em um inédito arranjo de signos. Esse desenho altera a configuração usual a ponto de

5 “[A arte] se instala e nos instala num mundo cuja chave não temos, [podendo] ensinar-nos a ver e finalmente fazer-nos pensar como nenhuma obra analítica consegue fazê-lo, porque a análise encontra no objeto apenas o que nele pusemos. O que há de imprevisto na comunicação literária, e de ambíguo, de irredutível à tese em todas as grandes obras de arte, não é uma fraqueza provisória de que se poderia esperar libertá-las, é o preço a ser pago para ter uma literatura, isto é, uma linguagem conquistadora, que nos introduza em perspectivas alheias, em vez de nos confirmar nas nossas” (MERLEAU-PONTY, I99I, p. 8I-82). 
esgarçá-la e alçar nova significação. A essa altura, o espírito do leitor se abre para a linguagem de Stela, ela o transformou e o tornou apto a adentrar em sua sutileza ${ }^{6}$.

\author{
Meu passado foi um passado de areia \\ Em mar de Copacabana \\ Cachoeira de Paulo Afonso \\ Bem dentro da Lagoa Rodrigo de Freitas \\ No Rio de Janeiro
}

O futuro eu queria

Ser feliz

E encontrar a felicidade sempre

E não perder nunca o gosto de estar gostando [...]

(PATROCÍNIO, 200I, p. 73).

De fato, o que se indicia aqui é a existência de duas linguagens que encerram um sentido temporal. Há a linguagem de depois - assim que é acedida, desaparece sob o sentido que passou a carregar - e há a linguagem que surge no momento da expressão cuja condução "vai justamente fazer-me passar dos signos ao sentido" (MERLEAU-PONTY, 20I2, p. 39). Em outras palavras, a linguagem obsessivamente persegue o sentido puro, não é limitada senão por si mesma e só pode ser compreendida na interação das partes, os signos (MERLEAU-PONTY, I99I). Não é possível enfrentarmos os signos ou as palavras de outro modo senão pela relação de coexistência que lhes confere sentido. Seu caráter diacrítico - compõe-se e organiza-se consigo mesmo - garante um aprendizado e uma compreensão que se realizam na própria maneira como a linguagem se articula, pelas modulações do aparelho expressivo, com as quais contribuo apelando para minhas experiências. Ao reconhecer algum resíduo aparentemente familiar, assim que o identifico no arranjo a mim apresentado, ele imediatamente transborda a configuração trivial ratificada como parte de minhas experiências cotidianas, para se desvelar em um sentido que me desafia com sua proposição inédita.

É assim que a linguagem poética de Stela do Patrocínio institui uma nova ordem relacional dos signos cujos sentidos surgem de sua reunião, mas nascem sobretudo dos vãos, das pausas, das modulações e dos silêncios que se abrem cedendo espaço para algo novo. E é nos outros que sua expressão ganha relevo, contorno, e se torna significação.

No caso da linguagem expressiva das obras de arte, elas são apercepções absolutamente pessoais (MERLEAU-PONTY, I980, p. II6). De certo modo, o que

6 "Mas a linguagem falante é a interpelação que o livro dirige ao leitor desprevenido, é aquela operação pela qual um certo arranjo dos signos e das significações já disponíveis passa a alterar e depois a transfigurar cada um deles, até finalmente secretar uma significação nova, estabelecendo no espírito do leitor, como um instrumento doravante disponível, a linguagem de Stendhal. Uma vez adquirida essa linguagem, posso perfeitamente ter a ilusão de tê-la compreendido por mim mesmo: é que ela me transformou e tornou-me capaz de compreendê-la” (MERLEAU-PONTY, 20I2, p. 43). 
nos desafia está relacionado à aparição de um sentido que nos interroga sobre sua verdade. Mas, como capturá-lo, se a expressão é uma possibilidade que anseia por quem a aperceba, portanto, permanentemente em aberto? Seria preciso retomar o percurso de seu autor, imanente na obra? E como recuperá-lo na obra, se ela, incontinente, ultrapassa seu criador? Mais uma vez estamos diante da dificuldade de relativizarmos o que nos interroga quando nos deparamos com obras de expressão. Essa resistência é o apego às "ideias muito possuídas” (MERLEAU-PONTY, 2009), que só pode ser vencido se admitirmos que ele é insuficiente para suprir a riqueza de sentidos de uma obra de pensamento, pois é tagarelice, é apenas fala sobre falas: normativa, esvaziada e previsível.

O acesso à obra é um mergulho na intenção de outrem. Tentando fugir de meus próprios pensamentos, me dou conta da perspectiva de uma alteridade que só é possível por mim mesma7. Entretanto, esse caminho só se oferece como efetiva possibilidade quando a linguagem é familiar. Assim, após reconhecida, é retomada e segue paulatinamente arriscada em seu equilíbrio estável.

Aos poucos, passa a ser descentrada e organizada em um novo equilíbrio que desafia o leitor. Sua função segunda, constituinte, só se apresenta a partir do momento em que supomos dada a primeira, já constituída, então alçamos uma consciência mais sutil sobre a verdade que ela porta e colocamos a linguagem antes da linguagem, pois, antes de ter significação, a linguagem é significação (MERLEAU-PONTY, 2OI2, p. 45).

$\mathrm{O}$ caminho que conduz à intenção de um artista é incerto e arriscado. É incerto porque não se sabe precisamente por que vias seguirá; e é arriscado porque esse percurso poderá solicitar o empenho e a coragem de vir a enfrentar um caminho inesperado. E, enfim, doravante seguirá plasmado na existência do leitor.

\author{
Não deu tempo \\ Eu estava tomando claridade e luz \\ Quando a luz apagou \\ A claridade apagou \\ Tudo ficou nas trevas \\ Na madrugada mundial \\ Sem luz \\ (PATROCÍNIO, 200I, p. I24).
}

Para alguns, a penúria dos asilados em instituições totais, como Stela do Patrocínio, Lima Barreto, Ernesto Nazareth e Arthur Bispo do Rosario ${ }^{8}$, só os solicita no desempenho de um papel testemunhal, como quem observa A incredulidade de

7 Diz o filósofo: "A leitura é um confronto entre os corpos gloriosos e impalpáveis de minha fala e da fala do autor” (MERLEAU-PONTY, 20I2, p. 44).

8 Os autores de literatura, artes visuais e música são mencionados a título de demonstração da amplitude dos efeitos desastrosos da política asilar, em meados do século passado. Do ponto de vista pessoal, da penalização dos sujeitos - trato aqui especialmente do caso de Stela do Patrocínio -, mas as baixas se avolumaram a tal ponto, que, além das irreparáveis perdas humanas, os prejuízos alcançaram o campo da cultura e da arte. 
São Tomé, de Caravaggio, ou Tiradentes esquartejado, de Pedro Américo, no conforto do museu, e suspira aliviado pois o martírio lhe é alheio. Porém, é irrecusável, há algo de uma certa dor, de determinada solidão na poesia de Stela, que não se explica essencialmente no diagnóstico maldado da instituição total, em um período de nossa história envergonhado de sua vocação eugênica. Esses heróis de sua própria epopeia transferem para as obras "a hereditariedade sensações ricas, emoções arrebatadoras, um vago sentimento de angústia ou de mistério que desorganizam sua vida voluntária e separam-na dos homens; esses dons, porém, só chegam à obra pelo ato de expressão e em nada participam das dificuldades como das virtudes deste ato" (MERLEAU-PONTY, I980, p. I2I). Esse insumo existencial é um presente que a natureza e a história lhe proporcionaram, e ele, às obras, para decifração em um sentido figurado e inédito, que passa a existir após seu surgimento como obras. Assim, o sentido não está posto em dado ponto, ou nas coisas. O sentido é um despertar de experiências, e um enraizar-se em outras consciências: "Se a obra é bem-sucedida, tem o estranho poder de transmitir-se por si" (MERLEAU-PONTY, I980, p. I2I), e o espectador retoma e reúne vidas, que antes estavam separadas, em um sentido que passa a habitá-las?.

Seguimos destinados à retomada de expressões cujos sentidos nos penetram e passam a nos habitar. Resta nos empenharmos e desfrutarmos dessa liberdade, nos interrogando sobre aquilo que não se explica pela vida ou pela história de seus protagonistas, ainda que a obra tenha exigido uma vida dramática para existir. É preciso consciência sobre a oportunidade que se oferece a uma liberdade, à qual, certamente, não estamos inexoravelmente condenados, porém, há inúmeras ocasiões em que ela só seria passível de realização inaudita através da arte. Em geral, nas demais instâncias da vida, a liberdade tornou-se ilusória ou compulsória, é apenas liberdade assistida. Infelizmente, em geral, as obras estão convertidas em espetáculo, em nossa cultura contemporânea.

Empenho minha verdade à dessa alteridade que resolvi visitar. Estou só e não estou. Há muitos comigo, de alguma forma, passeando uma presença-ausente em suas expressões imbricadas às minhas experiências. Eis que esses tantos surgem sob as letras que saltam dos poemas de Stelas, dos pontos bordados de Bispos ou das notas de Nazareths urgindo minha presença:

Olha quantos estão comigo

Estão sozinhos

Estão fingindo que estão sozinhos

Para poder estar comigo

(PATROCÍNIO, 200I, p. 65).

Merleau-Ponty nos deixa um alento e um alerta: desde o nascimento sou projeto

9 “A expressão jamais é absolutamente expressão, o exprimido jamais é completamente exprimido; à linguagem é essencial que a lógica de sua construção jamais seja das que se podem colocar em conceitos, e à verdade, que jamais seja possuída, mas apenas transpareça através da lógica confusa de um sistema de expressão que traz os vestígios de um outro passado e os germes de um outro futuro” (MERLEAU-PONTY, 20I2, p. 77). 
e, dado esse fato, interpõe-se uma dificuldade: distinguir o dado e o criado. Há indivíduos que trazem em germe, a obra de arte que irão realizar. No entanto, não há determinação, ainda que nunca deixem de ser quem são, com toda a dor e a beleza que essa encarnada liberdade implica. Está em nossas mãos deixar que a liberdade atue e sobrevenha, se possível em obra, na beleza da expressão de uma obra de arte.

\section{SOBRE A AUTORA}

SOLANGE DE OLIVEIRA é docente do Departamento de Artes Visuais e Design da Universidade Federal de Sergipe (UFS) e pesquisadora na área de estética e filosofia contemporânea, com ênfase em formas expressivas. sololiveira@usp.br https://orcid.org/o0oo-oooI-86I5-928X

\section{REFERÊNCIAS}

BERGSON, Henri. O pensamento e o movente: ensaios e conferências. Tradução Bento Prado Neto. São Paulo: Martins Fontes 2006.

MERLEAU-PONTY, Maurice. A dúvida de Cézanne. In: MERLEAU-PONTY, Maurice. Os pensadores. Tradução e notas de Marilena Chauí e Nelson Alfredo Aguilar. São Paulo: Nova Cultural, I980, p. II3-I26.

MERLEAU-PONTY, Maurice. Signos. São Paulo: Martins Fontes, I99I.

MERLEAU-PONTY, Maurice. Fenomenologia da percepção. São Paulo: Martins Fontes, 2006.

MERLEAU-PONTY, Maurice. O visível e o invisível. São Paulo: Perspectiva, 2009.

MERLEAU-PONTY, Maurice. A prosa do mundo. Tradução: Paulo Neves. Edição e posfácio: Claude Lefort. São Paulo: Cosac Naify, 2012.

OLIVEIRA, Solange de. Arthur Bispo do Rosario além dos muros da Colônia. Psicologia USP. v. 27, n. 3, dez. 20I6, p. 395-403. https://doi.org/Io.I590/oI03-6564201300I7.

PAREYSON, Luigi. Os problemas da estética. São Paulo: Martins Fontes, 200I.

PATROCÍNIO, Stela. do. Reino dos bichos e dos animais é o meu nome. Organização e apresentação: Viviane Mosé. Rio de Janeiro: Azougue Editorial, 200I.

POMPERMAIER, Paulo Henrique. "Nega, preta, crioula”, a poeta Stela do Patrocínio atravessou com sua fala a própria condição social, a vida no hospício e o precipício humano. Cult, UOL, 9 de maio de 20I7. Disponível em: https://revistacult.uol.com.br/home/stela-do-patrocinio-vozes-subterraneas/. Acesso em: 25 maio 202I. 